\title{
Overexpression of Hormone-sensitive Lipase Prevents Triglyceride Accumulation in Adipocytes
}

\author{
Carole Sztalryd, Michael C. Komaromy, ${ }^{\star}$ and Fredric B. Kraemer \\ Division of Endocrinology, Gerontology, and Metabolism, Department of Medicine, Stanford University School of Medicine, \\ Stanford, California 94305; Department of Veterans Affairs Medical Center, Palo Alto, California 94304; and *Research Institute, \\ Palo Alto Medical Foundation, Palo Alto, California 94301
}

\begin{abstract}
Hormone-sensitive lipase (HSL) is a cytosolic neutral lipase that hydrolyzes intracellular stores of triglycerides within adipocytes and is thought to be the rate limiting enzyme in lipolysis; however, direct evidence to prove this concept has been lacking. The present study was designed to establish the function of HSL in adipocytes. A 2360-bp fragment containing the entire HSL coding region was cloned into the vector pCEP4 and was used to transfect the 3T3-F442A adipogenic cell line. Nondifferentiated, transfected cells were screened for HSL overexpression by indirect immunofluorescence microscopy and confirmed by immunoblotting cell extracts with anti-HSL/fusion protein antibodies and by Northern blots for HSL mRNA. Stable transfectants overexpressing HSL were obtained and cloned. Compared with undifferentiated 3T3-F442A cells transfected with pCEP4 not containing the insert (vector alone) where HSL expression was very low, undifferentiated HSL transfectants had up to a 100-fold increase in HSL activity. Likewise, immunoreactive HSL protein and HSL mRNA levels were increased up to 100-fold in HSL transfectants. When confluent cells were allowed to differentiate by exposure to insulin, HSL expression increased in vector alone transfected cells, but remained below that observed in HSL transfectants. A similar degree of differentiation was seen in both vector alone and HSL transfectants when based on the induction of lipoprotein lipase. Cellular triglyceride content increased dramatically in the vector alone transfected cells while triglyceride content was markedly reduced in the HSL transfectants. The expression of late markers of adipocyte differentiation, such as aP2 and GPDH, was diminished and appeared to vary with the degree to which HSL was overexpressed and the cellular triglyceride content was reduced. Thus, the overexpression of HSL in 3T3-F442A cells prevents differentiated adipocytes from taking on the appearance of fat cells, i.e., accumulating triglyceride. Furthermore, the overexpression of HSL directly or indirectly attenuates the expression of several genes that appear during late adipocyte differentiation. (J. Clin. Invest. 1995. 95:26522661.) Key words: hormone-sensitive lipase - adipocytes • immunoblot $\cdot$ mRNA $\cdot$ recombinant DNA
\end{abstract}

Address correspondence to Fredric B. Kraemer, M.D., Division of Endocrinology, S-005, Stanford University Medical Center, Stanford, CA 94305-5103. Phone: 415-493-5000, ext. 3184; FAX: 415-852-3263.

Received for publication 6 October 1994 and in revised form 23 December 1994.

The Journal of Clinical Investigation, Inc.

Volume 95, June 1995, 2652-2661

\section{Introduction}

Free fatty acids are a major energy source for most tissues. Circulating FFA in plasma are derived from the breakdown of stored triacylglycerols in adipose tissue $(1,2)$. It has been suggested that an increased metabolic activity (i.e., a greater release of FFA) of internal fat depots is responsible for the observations linking central obesity with an increased prevalence of hyperlipidemia, atherosclerosis, diabetes mellitus, insulin resistance, and hypertension $(3,4,5)$. The major enzyme responsible for the mobilization of FFA from adipose tissue is thought to be hormone-sensitive lipase (HSL), ${ }^{1}$ whose name was coined to reflect the ability of hormones such as catecholamines, ACTH, and glucagon to stimulate the activity of this intracellular neutral lipase (6).

HSL catalyzes the first, rate-limiting step in lipolysis by cleaving the first ester-bond of triacylglycerols $(7,8)$. In adipose tissue, HSL also catalyzes the second step of the lipolytic reaction by hydrolyzing diacylglycerol to monoacylglycerol ( 7 , 8). Although HSL is capable of hydrolyzing monoacylglycerols to FFA, the final step of the lipolytic process is carried out by another enzyme, monoacylglycerol lipase $(9,10)$. This is due to the specificity of HSL for 1,(3)-monoacylglycerols, while the main product of the hydrolysis of triacylglycerols is 2monoacylglycerol (11). Indeed, the findings that monoacylglycerol accumulates in vitro in the presence of HSL when monoacylglycerol lipase is absent (10) and that monoacylglycerol lipase does not appear to be hormonally regulated have formed the basis for concluding that HSL is the rate limiting enzyme in lipolysis. The activity of HSL is regulated acutely via phosphorylation-dephosphorylation reactions. The activation of HSL by fast-acting lipolytic hormones (catecholamines, glucagon, ACTH) involves a hormone/receptor-induced increase in the cellular concentration of cyclic AMP (12) which activates cyclic AMP-dependent protein kinase (PKA). PKA then phosphorylates HSL (12), resulting in an increase in hydrolytic activity $(13,14)$. Recently, it has been observed that HSL activity in adipose tissue can be regulated by mechanisms in addition to posttranslational phosphorylation and dephosphorylation. Thus, food deprivation (15) and streptozotocininduced diabetes (16) in rats cause an increase in the steady state levels of HSL mRNA and the amount of immunoreactive HSL protein that parallel the rise in HSL activity and the reduction in adipose cell size observed with both of these physiological maneuvers. These results suggest that the amount of HSL

1. Abbreviations used in this paper: aP2, adipocyte lipid binding protein; GPDH, glycerol-3-phosphate dehydrogenase; HSL, hormone-sensitive lipase; LPL, lipoprotein lipase; PKA, cyclic AMP-dependent protein kinase. 
expressed in an adipose cell can influence the rate of lipolysis of the cell and the amount of lipid the cell is able to accumulate.

The current studies were conducted to address directly the functional significance of HSL expression in adipocytes. For this purpose, the murine adipogenic cell line, 3T3-F442A, which was originally selected from mutagenized $3 \mathrm{~T} 3$ fibroblasts on the basis of their propensity to differentiate into adipocytes (17, 18), was stably transfected to constitutively overexpress HSL. The 3T3-F442A cells have the highest rate of conversion into adipose cells of all continuous adipogenic cell lines and undergo differentiation when grown in fetal calf serum with insulin. The ability of the adipogenic cells overexpressing HSL to differentiate and achieve maturation was tested. Adipocyte differentiation is a complex process that first involves commitment of the cell to differentiate, followed by the expression of early and late markers of differentiation, such as lipoprotein lipase (LPL), adipocyte lipid binding protein (aP2), glycerol-3-phosphate dehydrogenase (GPDH), HSL, and adipsin (19). Concomitantly, the phenotypic expression of adipocytes is characterized by cellular triglyceride accumulation. The results of the current studies show that the overexpression of HSL is able to prevent the accumulation of triglyceride within differentiated adipocytes. Although not accumulating triglyceride, the adipocytes overexpressing HSL are able to express some markers of differentiation; however, the expression of several late markers of differentiation are attenuated.

\section{Methods}

Chemicals. Reagents were obtained from the following sources: bovine serum albumin (fraction V) (Intergen Co., Purchase, NY); sodium deoxycholate, Triton X-100, L- $\alpha$ phosphatidylcholine, cholesterol oleate, leupeptin, aprotinin, anti-rabbit IgG FITC conjugate, hygromycin B (Sigma Chemical Co., St. Louis, MO); cholesterol $\left[1-{ }^{14} \mathrm{C}\right]$ oleate, glycerol tri $\left[9,10(n)-{ }^{3} \mathrm{H}\right]$ oleate, $\left[\mathrm{U}-{ }^{14} \mathrm{C}\right]$ glucose (E.I. Dupont de $\mathrm{Ne}-$ mours and Co., Boston, MA); fetal bovine serum (Gemini Bio-Products, Inc., Calabasas, CA); Dulbecco's Modified Eagle's medium, lipofectin reagent (GIBCO BRL, Grand Island, NY); ECL western blotting detection reagents, horseradish peroxidase-linked whole antibody anti-rabbit IgG, $\left[\alpha-{ }^{32} \mathrm{P}\right]-\mathrm{dCTP},\left[{ }^{32} \mathrm{P}\right]$ orthophosphate (Amersham Life Sciences Products, Arlington Heights, IL); nitrocellulose paper (Schleicher and Schuell, Keene, NH); oligolabeling kit (Pharmacia LKB Biotechnology, Piscataway, NJ ). All other chemicals were obtained from standard commercial sources.

Plasmid construction. A full-length cDNA of rat HSL (20) was kindly obtained from Drs. C. Holm, P. Belfrage, and M. Schotz (University of Lund, Lund, Sweden, and UCLA). The coding region in the 3225-bp clone runs from base 616 to base 2887. Since no appropriate restriction enzyme sites existed in the HSL cDNA for subcloning while minimizing the amount of flanking sequences, two oligonucleotide primers corresponding to bases 581-600 and bases 2904-2923 of the HSL cDNA were synthesized containing HindIII and XhoI sites in the upstream and downstream primers, respectively. These were used in a polymerase chain reaction with the thermostable Pfu DNA polymerase (Stratagene, La Jolla, CA) to generate a 2360-bp fragment containing the entire HSL coding region (21). After digestion with HindIII and Xhol, the fragment was cloned into the pCEP4 vector (In Vitrogen, San Diego, CA). pCEP4 is an Epstein-Barr virus-based vector that places the cloned fragment under the transcriptional control of the immediate early gene of the human cytomegalovirus promoter and contains polyadenylation signals as well as the ampicillin and hygromycin B-resistance genes. pCEP4-HSL clones were isolated and sequenced to ascertain that no mutations had been introduced during amplification.

Cell culture and transfection. 3T3-F442A murine adipocytes (kindly provided by Dr. H. Green, Harvard University) were grown in DME containing $4.5 \mathrm{~g} /$ liter glucose and $25 \mathrm{mM}$ HEPES, supplemented with $10 \%$ defined fetal calf serum, penicillin $(10,000 \mathrm{U} / \mathrm{ml})$ and streptomycin $(10,000 \mu \mathrm{g} / \mathrm{ml})$. In order to induce adipocyte differentiation, cells that had reached confluence were treated with insulin $\left(10^{-7} \mathrm{M}\right)$ for $48 \mathrm{~h}$. After exposure to insulin, cells were allowed to continue differentiation in media without added insulin for an additional 8-10 d. In some experiments the media during differentiation were supplemented with $10 \%$ Intralipid. Transfection of undifferentiated 3T3-F442A cells was performed by incubating $1 \times 10^{5}$ cells in a $60-\mathrm{mm}$ dish with $2 \mu \mathrm{g}$ of pCEP4-HSL in $10 \mu \mathrm{l}$ of lipofectin reagent. After $24 \mathrm{~h}$ of incubation, a selection medium composed of DME supplemented with $10 \%$ FCS and hygromycin B $(200 \mu \mathrm{g} / \mathrm{ml})$ was applied and cells maintained in this media thereafter. Before reaching confluence, antibiotic resistant cells were trypsinized and plated at a cell density of 1-5 cells per well in 96-multiwell dishes. Screening for HSL expression was then performed by immunofluorescence staining (described below). Cells expressing HSL were subsequently subcloned at a cell density of 1 cell per 5 wells of a 96-multiwell dish to isolate clonal cell lines (22). Subclones were rescreened for HSL expression and cells displaying a range of HSL expression were expanded.

Indirect immunofluorescence and immunoblotting. Indirect immunofluorescence detection of HSL was used as a means of screening for HSL-positive clones. Cells were first fixed with 3\% paraformaldhyde for $10 \mathrm{~min}$ on ice and permeabilized with $0.02 \%$ Triton X-100 for 30 $\mathrm{min}$ at room temperature. Fixed cells were incubated at $4^{\circ} \mathrm{C}$ overnight with rabbit anti-rat $\mathrm{HSL} /$ fusion protein IgG (23) at 1:500 dilution, washed and then incubated with an anti-rabbit IgG FITC conjugate ( $1: 160$ dilution) for $1 \mathrm{~h}$. Visualization of the cells was performed using an inverted fluorescence microscope (Nikon). Confocal microscopy imaging was performed at the Cell Science Imaging Facility (Department of Molecular and Cellular Physiology, Stanford University) and involved the use of a custom built, mirror scanning, single beam laser confocal microscope designed by Dr. S. J. Smith (Stanford University). The equipment uses low light $(<100 \mu$ watt beam power $)$ and is attached via a Nikon inverted microscope to laser-scanned Nomarski DIC. The samples were excited with blue light $(488 \mathrm{~nm})$ and observations were made at an emission wavelength of $510-550 \mathrm{~nm}$. The fluorescent signal was filtered by a dichroic mirror (510). A Nikon $60 \mathrm{X}$ (NA 1.4) planapo objective was used. The fluorescent and Nomarski images were stored in a computer and subsequently merged using Adobe Photoshop ${ }^{\circledR}$ (Adobe Systems Inc, Mountain View, CA); color was assigned arbitrarily. For immunoblotting, cells were scraped and briefly sonicated ( $3 \mathrm{~s}$ ) in $1 \mathrm{ml}$ of ice cold lysis buffer containing $0.15 \mathrm{M} \mathrm{NaCl}$, $3 \%$ Triton X-100, 0.1\% lauryl sarcosyl, and $1 \mathrm{U} / \mathrm{ml}$ leupeptin. All homogenates were centrifuged at $10,000 \mathrm{~g}$ for $15 \mathrm{~min}$. The infranatant below the fat cake was removed and kept frozen at $-80^{\circ} \mathrm{C}$. Samples were electrophoresed on $10 \%$ polyacrylamide gels under reducing conditions, transferred to nitrocellulose, incubated with anti-rat HSL/fusion protein IgG, and visualized by chemiluminescence as described previously (23). The relative amounts of immuno-detectable HSL contained in each lane were determined by scanning with an LKB Ultra scan XL enhancer laser densitometer and Gel scan XL software (Pharmacia LKB Biotechnology, Piscataway, NJ) on a NEC computer.

Immunoprecipitation. Immunoprecipitation was performed as previously described (23). Cells were incubated in DME with $10 \%$ FCS containing $200 \mu \mathrm{Ci} / \mathrm{ml}$ of [ ${ }^{32} \mathrm{P}$ ] orthophosphate for $60 \mathrm{~min}$ before exposure to $1 \times 10^{-5} \mathrm{M}$ forskolin for $10 \mathrm{~min}$. The incubations were performed at $37^{\circ} \mathrm{C}$ under an atmosphere of $95 \%$ air $/ 5 \% \mathrm{CO}_{2}$. At the end of the incubations, cells were washed twice with phosphate buffered saline containing $5 \mathrm{mM} \mathrm{NaF}$ and $1 \mathrm{mM}$ benzamidine and scraped into $0.5 \mathrm{ml}$ of ice-cold lysis buffer $(0.15 \mathrm{M} \mathrm{NaCl}, 3 \%$ Triton X-100, $0.1 \%$ lauryl sarcosyl, $1 \mathrm{mM}$ PMSF, $1 \mathrm{U} / \mathrm{ml}$ leupeptin, $0.2 \mathrm{mg} / \mathrm{ml}$ aprotinin, and $5 \mathrm{mM} \mathrm{NaF}$ ). Samples were precleared with Pansorbin and then incubated with rabbit polyclonal anti-HSL/fusion protein $\operatorname{IgG}(\sim 0.5$ $\mu \mathrm{g} / \mathrm{ml})$ at $4^{\circ} \mathrm{C}$ for $12-14 \mathrm{~h}$. The immune complex was isolated by adding Pansorbin ( $500 \mu \mathrm{l} /$ tube $)$ for $30 \mathrm{~min}$ at $4^{\circ} \mathrm{C}$ and then centrifuging at $10,000 \mathrm{~g}$ for $15 \mathrm{~min}$. The pellet was washed twice with a buffer containing $0.1 \mathrm{M}$ Tris- $\mathrm{HCl}$ ( $\mathrm{pH} 7.5$ ), $0.05 \mathrm{M} \mathrm{LiCl}, 5 \mathrm{mM} \mathrm{NaF}, 1 \mathrm{mM}$ 

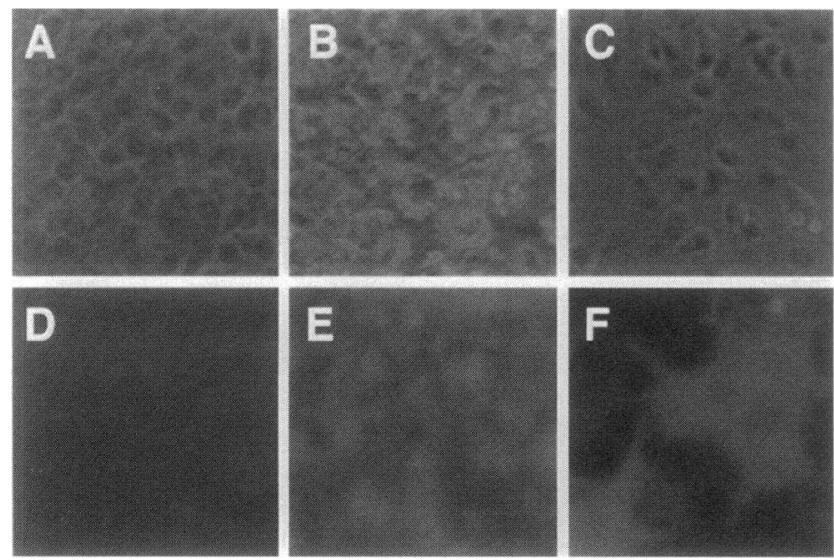

Figure 1. Immunocytochemistry of HSL in 3T3-F442A adipocyte cell lines. $A-C$ are phase contrast microscopy of undifferentiated 3T3F442A cells $(A)$, differentiated 3T3-F442A cells $(B)$, and undifferentiated 3T3-F442A cells transfected with pCEP4-HSL $(C) . D-F$ are fluorescent microscopy of undifferentiated 3T3-F442A cells $(D)$, differentiated 3T3-F442A cells $(E)$, and undifferentiated 3T3-F442A cells transfected with pCEP4-HSL $(F)$. For differentiated cells, confluent cells were exposed to insulin for $48 \mathrm{~h}$ to stimulate differentiation and then assayed after 8-10 d. After permeabilization with $0.2 \%$ Triton $X$ 100 , the cells were incubated sequentially with rabbit serum, rabbit anti$\mathrm{HSL} /$ fusion protein IgG, and goat anti-rabbit IgG-FITC fluorochrome conjugate. The slides were then examined under a Nikon fluorescence microscope. $A-E: \times 62.5 ; F: \times 125$.

PMSF, $1 \mathrm{U} / \mathrm{ml}$ leupeptin, $0.2 \mathrm{mg} / \mathrm{ml}$ aprotinin, $1 \%$ Triton $\mathrm{X}-100,0.5 \%$ deoxycholic acid and $0.1 \%$ SDS. The pellet was resuspended in the same buffer containing $1 \% \beta$-mercaptoethanol and $1 \%$ SDS, boiled for $5 \mathrm{~min}$ and electrophoresed on $10 \%$ polyacrylamide gels containing $0.1 \%$ SDS. After drying, the gels were visualized by exposure to a PhosphorImager ${ }^{\circledR}$ (Molecular Dynamics, Sunnyvale, CA).

RNA isolation and measurement. Total cellular RNA was extracted by $\mathrm{CHCl}_{3}$ :phenol extraction as described (24). RNA pellets were dissolved in sterile water and quantified by standard UV absorbency. After denaturation with $1 \mathrm{M}$ glyoxal, 50\% dimethyl sulfoxide, RNA was analyzed by Northern blot hybridization after electrophoresis on $1 \%$ agarose gels. Probes used were: rat HSL cDNA; rat GPDH and aP2 cDNAs (a kind gift of Dr. F. Torti, Stanford University). Probes were labeled with $\left[{ }^{32} \mathrm{P}\right] \mathrm{dCTP}$ to a specific activity of $1-2 \times 10^{9} \mathrm{dpm} / \mu \mathrm{g}$ with an oligolabeling kit. Prehybridization and hybridization procedures were performed as previously described (24). Autoradiographs were obtained by exposure to Kodak XAR-film with an intensifying screen at $-80^{\circ} \mathrm{C}$ for $1-2 \mathrm{~d}$. The autoradiographs were analyzed by scanning as previously described.

Enzyme activities and lipid synthesis. Measurement of HSL activity was performed using a cholesterol- $\left[{ }^{14} \mathrm{C}\right]$ oleate emulsion as described previously (23). Cells were scraped into $1 \mathrm{ml}$ of $50 \mathrm{mM}$ Tris- $\mathrm{HCl}$ and $1 \mathrm{mM}$ EDTA containing $1 \mathrm{U} / \mathrm{ml}$ leupeptin and homogenized in a conical homogenizer for 10 stokes. After centrifuging the homogenates at $14,000 \mathrm{~g}$ for $15 \mathrm{~min}$, the infranatants were carefully removed, and aliquots (50-100 $\mu \mathrm{l})$ were assayed in duplicate for neutral cholesterol esterase activity (23). Heparin-releasable LPL activity was assayed using a radioenzymatic assay with a glycerol-stabilized triolein substrate emulsion as described previously $(25,26)$, and expressed as $\mathrm{mU}$ of FFA released/h per mg protein. Glycerol-3-phosphate dehydrogenase was assayed according to the method of Wise and Green (27). Lipid synthesis was measured as the incorporation of $\left[{ }^{14} \mathrm{C}\right]$ glucose into lipids (28). Cells were incubated with $1 \mu \mathrm{Ci} / \mathrm{ml}\left[\mathrm{U}-{ }^{14} \mathrm{C}\right.$ ] glucose for $4 \mathrm{~h}$ at $37^{\circ} \mathrm{C}$. After scraping the cells into normal saline, the lipids were extracted by the Folch method (29) and separated by thin layer chromatography first using acetone until the solvent migrated $1 \mathrm{~cm}$ and then

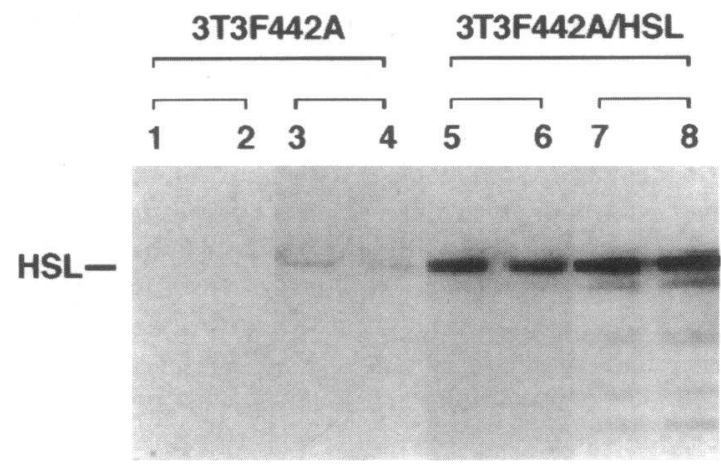

Figure 2. Immunoblot of HSL in 3T3-F442A adipocyte cell lines. Lanes 1 and 2, undifferentiated cells transfected with pCEP4 vector without insert; lanes 3 and 4, differentiated cells transfected with pCEP4 vector without insert; lanes 5 and 6 , undifferentiated cells transfected with pCEP4-HSL; lanes 7 and 8, differentiated cells transfected with pCEP4HSL. For differentiated cells, confluent cells were exposed to insulin for $48 \mathrm{~h}$ to stimulate differentiation and then assayed after 8-10 d. Cell extracts $(25 \mu \mathrm{g})$ were electrophoresed on SDS-PAGE, transferred to nitrocellulose filters, immunoblotted with anti-HSL/fusion protein IgG, and visualized by enhanced chemiluminescence. The film was developed after a 1-min exposure.

heptane:ethyl ether:acetic acid (75:25:2) as the solvent system. The locations corresponding to the migration of purified lipid standards were scraped and the radioactivity determined in a liquid scintillation spectrophotometer.

Other assays. Protein was measured with a bicinchoninic acid protein assay kit (Pierce Chemical Co., Rockford, IL). Triglycerides were assayed using a triglyceride kit from Sigma Diagnostic. Oil red $O$ staining was performed after counter staining with hematoxylin-eosin (30).

Statistical analysis. Data are expressed as mean \pm SEM. Statistical analyses were performed by analysis of variance and comparisons among groups by Fisher's Protected LSD using StatView ${ }^{\mathrm{TM}}$ software (ABACUS Concepts, Berkeley, CA) on a Macintosh II computer.

\section{Results}

Establishment of stable HSL transfectants. After transfection with pCEP4-HSL and selection with hygromycin B, 350 colonies were obtained, 30 of which stained positively with antirat HSL fusion protein antibodies. An example of the immunocytochemistry of HSL in 3T3-F442A cells is displayed in Fig. 1. $A-C$ are phase contrast microscopy images and $D-F$ are fluorescent microscopy images of cells incubated with antiHSL/fusion protein IgG. Undifferentiated, control 3T3-F442A cells contain no lipid $(A)$ and do not have detectable HSL $(D)$, while differentiated, control 3T3-F442A cells have discernible, large lipid droplets $(B)$ and detectable HSL $(E)$, although the signal is somewhat diffuse and of low intensity. In contrast, undifferentiated 3T3-F442A cells transfected with pCEP4-HSL have no lipid droplets $(C)$, but display high intensity HSL immunofluorescence $(F)$.

To quantitate the differences in HSL expression among the 3T3-F442A cell lines, the amount of immunoreactive HSL protein in control 3T3-F442A cells and HSL transfectants having the highest expression of HSL (clone 2D) was determined by immunoblotting equal amounts of cell protein extracts with rabbit polyclonal anti-rat HSL fusion protein antibodies (Fig. 2). As reported previously $(7,23,31)$, HSL appears as a major band at approximately 84 kilodalton in murine adipocytes. Un- 


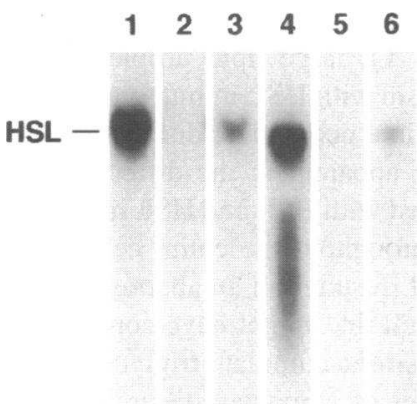

Figure 3. Northern blot of HSL mRNA in adipocytes. Lane 1 , rat epididymal fat; lane 2 , undifferentiated 3T3-F442A cells transfected with pCEP4 vector without insert; lane 3, differentiated 3T3-F442A cells transfected with pCEP4 vector without insert; lane 4, undifferentiated 3T3-F442A cells transfected with pCEP4-HSL; lane 5 , undifferentiated control

3T3-F442A cells; lane 6, differentiated 3T3-F442A control cells. For differentiated cells, confluent cells were exposed to insulin for $48 \mathrm{~h}$ to stimulate differentiation and then assayed after 8-10 d. Total RNA ( 20 $\mu \mathrm{g}$ ) was electrophoresed on $1 \%$ agarose gels, transferred to nylon and hybridized with a full length HSL cDNA. Ethidium bromide staining demonstrated equivalent amounts of RNA in each lane (not shown).

differentiated control cells had no detectable HSL (lanes 1 and 2 ), while HSL was easily detectable in control cells that were $10 \mathrm{~d}$ postconfluence and that had differentiated (lanes 3 and 4 ). In comparison, HSL was expressed $\sim 100$-fold more in the HSL transfectants and to a similar degree in undifferentiated transfectants (lanes 5 and 6 ) and postconfluent differentiated transfectants (lanes 7 and 8 ). HSL activity paralleled the amount of HSL protein seen, with undifferentiated control cells hydrolyzing $\sim 2 \mathrm{nmol} / \mathrm{h}$ per $\mathrm{mg}$ protein, differentiated control cells hydrolyzing $\sim 38 \mathrm{nmol} / \mathrm{h}$ per $\mathrm{mg}$ protein, and HSL transfectants hydrolyzing $260 \mathrm{nmol} / \mathrm{h}$ per mg protein. In order to document the changes in HSL mRNA expression in the different adipocytes, a Northern blot analysis was performed (Fig. 3 ). As seen for HSL protein and activity, HSL mRNA expression is undetectable in undifferentiated control 3T3-F442A cells and increases with differentiation. HSL mRNA is also not expressed in undifferentiated cells transfected with the pCEP4 vector lacking the HSL insert and increases similarly to that in control cells when these vector alone transfected cells are allowed to differentiate. In contrast, undifferentiated cells transfected with HSL have a markedly increased HSL mRNA expression. Thus, stably transfected 3T3-F442A adipocytes have been isolated that overexpress HSL mRNA and this HSL mRNA is translated into increased amounts of HSL protein that is enzymatically active.

Adipocyte differentiation. After reaching confluence, 3T3F442A cells will undergo differentiation when exposed to high concentrations of insulin. The differentiation process in adipocyte cell lines has been well characterized by an increase in expression of several lipogenic enzymes, with LPL expression being a consistent early marker of differentiation (19). To evaluate whether the HSL transfectants were differentiating, the time course of the expression of LPL activity in 3T3-F442A cells transfected with HSL was compared with cells transfected with the pCEP4 vector lacking the HSL insert (i.e., vector alone transfected). Cells were allowed to reach confluence and then exposed to $10^{-7} \mathrm{M}$ insulin on day 0 . LPL activity measured in vector alone transfected cells was minimum before confluence but increased sharply by day 4 , reaching a plateau by day 8 (Fig. 4). Although there was a slight delay in the emergence of LPL activity in the HSL transfectants, LPL activity reached similar levels in both HSL and vector alone transfected cells, substantiating that both cell lines were differentiating. As an

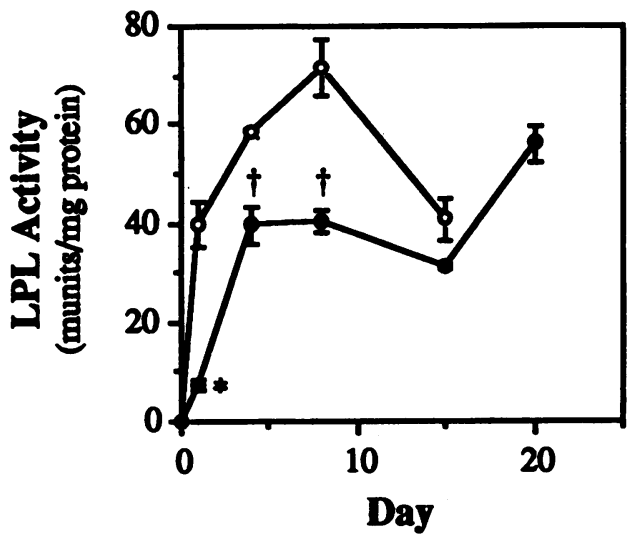

Figure 4. LPL activity in 3T3-F442A adipocytes transfected with pCEP4-HSL $(\bullet)$ or with pCEP4 vector without insert (vector alone, O). Confluent cells were exposed to insulin to stimulate differentiation and LPL activity measured at the indicated times as described in Methods. ${ }^{*} P<0.001$ compared to vector alone transfected cells; ${ }^{\dagger} P<0.05$ compared to vector alone transfected cells.

additional means of documenting changes in LPL expression, Northern blot analysis of LPL mRNA was performed on control, HSL transfectants, and vector alone transfected adipocytes both before and after differentiation (Fig. 5). As observed for LPL activity, LPL mRNA was not detectable in either undifferentiated control, HSL transfectants, or vector alone transfected adipocytes, but LPL mRNA expression increased similarly with differentiation in all three cell lines. Therefore, based on the appearance of the expression of LPL, transfection of 3T3F442A adipocytes with pCEP4, with or without the HSL insert, and selection of cells by hygromycin $B$ resistance does not appear to affect the ability of the adipocytes to differentiate.

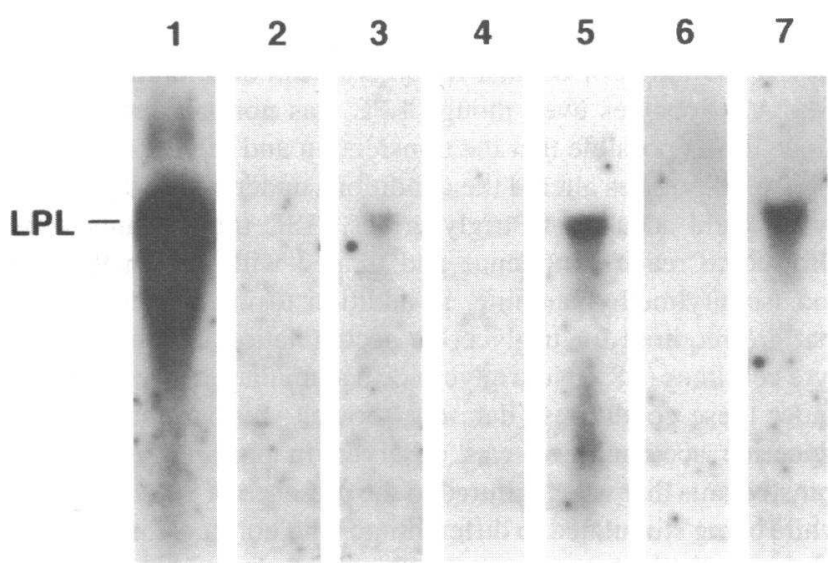

Figure 5. Northern blot of LPL mRNA in adipocytes. Lane 1, rat epididymal fat; lane 2, undifferentiated control cells; lane 3, differentiated control cells; lane 4, undifferentiated cells transfected with PCEP4-HSL; lane 5, differentiated cells transfected with pCEP4-HSL; lane 6 , undifferentiated cells transfected with pCEP4 vector without insert; lane 7, differentiated cells transfected with pCEP4 vector without insert. For differentiated cells, confluent cells were exposed to insulin for $48 \mathrm{~h}$ to stimulate differentiation and then assayed after 8-10 d. Total RNA (20 $\mu \mathrm{g}$ ) was electrophoresed on $1 \%$ agarose gels, transferred to nylon and hybridized with a full length LPL cDNA. Ethidium bromide staining demonstrated equivalent amounts of RNA in each lane (not shown). 


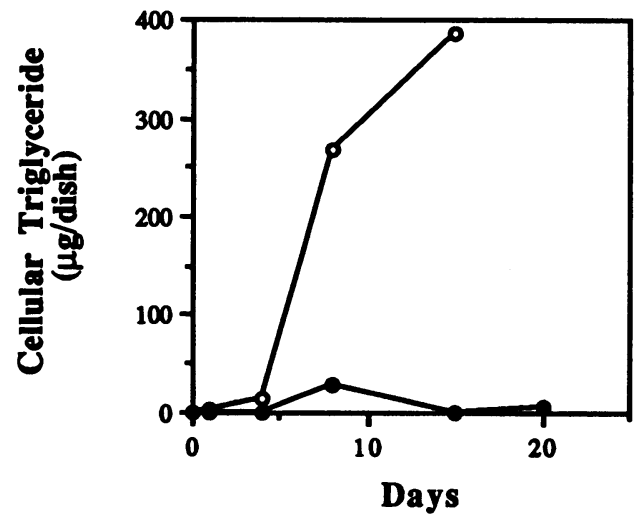

Figure 6. Cellular triglyceride accumulation in 3T3-F442A adipocytes transfected with pCEP4-HSL $(\bullet)$ or with pCEP4 vector without insert (vector alone, $\bigcirc$ ) during differentiation. Confluent cells were exposed to insulin to stimulate differentiation and cellular triglyceride content measured at the indicated times. Results are the average of duplicate wells.

While the HSL transfectants appeared to be able to differentiate normally, as assessed by LPL expression, the impact of HSL overexpression on the ability of the adipocytes to accumulate triglycerides was next examined by evaluating the time course of cellular triglyceride content in vector alone transfected cells and in HSL transfectants (Fig. 6). Cells were allowed to reach confluence and then exposed to $10^{-7} \mathrm{M}$ insulin on day 0 . While cellular triglyceride content increased dramatically in vector alone transfected cells after $5 \mathrm{~d}$ postconfluence, no triglycerides accumulated in the HSL transfectants even out to 20 d postconfluence. Representative photomicrographs of Oil Red $\mathrm{O}$ stained control 3T3-F442A cells after $8 \mathrm{~d}$ of differentiation and HSL transfectants $15 \mathrm{~d}$ postdifferentiation are shown in Fig. 7. While the control cells had accumulated numerous large lipid droplets, no lipid accumulation is discernible in the cells transfected with HSL. Thus, HSL over-expression prevented the accumulation of cellular triglycerides in differentiated 3T3F442A adipocytes even though LPL was normally expressed. Since it was possible that the transfection and selection of 3T3F442A adipocytes altered the conditions under which the adipocytes could accumulate triglycerides, HSL transfectants were allowed to reach confluence and treated with dexamethasone and isobutylmethylxanthine, in addition to insulin, conditions that are required for triglyceride accumulation of other adipocyte cell lines (18). No triglyceride accumulation was observed under these conditions (data not shown); furthermore, no triglyceride accumulation was observed in post-confluent HSL transfectants that were cultured in the presence of $10 \%$ Intralipid while being stimulated to differentiate with hormonal incubation (data not shown).

To explore potential mechanisms whereby the overexpression of HSL could prevent the accumulation of triglycerides in 3T3-F442A adipocytes, the intracellular localization of HSL in control 3T3-F442A adipocytes and HSL transfectants was examined using immunofluorescent confocal microscopy (Fig. 8). Control adipocytes and HSL transfectants were allowed to reach confluence and were stimulated to differentiate. $8 \mathrm{~d}$ after differentiation, cells were fixed and stained with anti-rat HSL fusion protein antibodies. The cells were examined by confocal microscopy to obtain Nomarski DIC and fluorescent images that were then merged by computer. In control differentiated 3T3-F442A adipocytes (Fig. $8 \mathrm{~A}$ ), large lipid droplets were observed throughout the cytoplasm with HSL immunoreactivity (depicted in green) faintly seen in a perinuclear distribution. In contrast, no lipid droplets were apparent in the differentiated 3T3-F442A adipocytes transfected with HSL and HSL immunoreactivity was now observed throughout the entire cell body. Thus, the overexpression of HSL resulted in an aberrant distribution of HSL throughout the cell that might have contributed to the inability of the adipocytes to accumulate triglycerides.

Since LPL is an early marker of adipocyte differentiation, some markers of later adipocyte differentiation were examined. Thus, Northern blot analyses of aP2 and GPDH mRNA levels in control and HSL transfectants were performed in both undifferentiated and differentiated cells (Fig. 9). Neither aP2 nor GPDH mRNA were detected in undifferentiated cells, whether control or HSL transfectants. Interestingly, although both aP2 and GPDH mRNA expression are induced during differentiation in control cells, neither aP2 nor GPDH mRNA is induced in the differentiated HSL transfectants that did not accumulate cellular triglycerides. GPDH activity paralleled the changes in GPDH mRNA levels (data not shown). These results suggest that the amount of triglyceride and/or some lipid intermediates are important in regulating the expression of some of the late markers of adipocyte differentiation.

The 3T3-F442A cells transfected with HSL used in these studies (clone 2D) were selected on the basis of their having the greatest overexpression of HSL in the undifferentiated state. In order to further support the view that the amount of HSL expression will determine the degree to which an adipocyte can maintain its pool of stored triglycerides, as well as the expression of later markers of adipocyte differentiation, an additional clone of 3T3-F442A cells transfected with HSL (clone E4) was studied. Clone E4 cells transfected with HSL expressed only $\sim 30 \%$ as much HSL as our high expressing clone 2D (HSL activity in clone $\mathrm{E} 4$ was $\sim 93 \pm 6.5 \mathrm{nmol} / \mathrm{h}$ per $\mathrm{mg}$ protein), but still markedly overexpressed HSL protein and HSL mRNA when compared with undifferentiated control cells (Fig. 10). As seen with control cells and HSL transfectant clone 2D, HSL transfectant clone E4 expressed LPL activity normally after differentiation (Fig. $11 A$ ). However, as opposed to HSL transfectant clone 2D where no cellular triglycerides accumulated after differentiation, cellular triglycerides did accumulate in HSL transfectant clone E4, but markedly reduced amounts compared to control or vector alone transfected cells (Fig. 11 $B$ ). When markers of adipocyte differentiation were examined, LPL mRNA expression increased similarly in differentiated 3T3-F442A cells, whether control or HSL transfectant clone E4 or clone 2D (Fig. $12 A$ ). Furthermore, as opposed to HSL transfectant clone 2D where late markers of adipocyte differentiation such as aP2 or GPDH mRNA could not be detected after differentiation, aP2 mRNA (Fig. $12 \mathrm{~B}$ ) and GPDH mRNA (Fig. $12 C$ ) increased in HSL transfectant clone E4 after differentiation, albeit at lower levels than seen in control cells. Thus, the level of expression of HSL appears both to determine the amount of cellular triglycerides an adipocyte can accumulate and to regulate, directly or indirectly, the expression of late markers of adipocyte differentiation.

While the ability of both of the HSL transfectant clones 2D and E4 to accumulate cellular triglycerides after differentiation was markedly reduced, it was important to document that the inability of the transfected cells to accumulate triglycerides was 

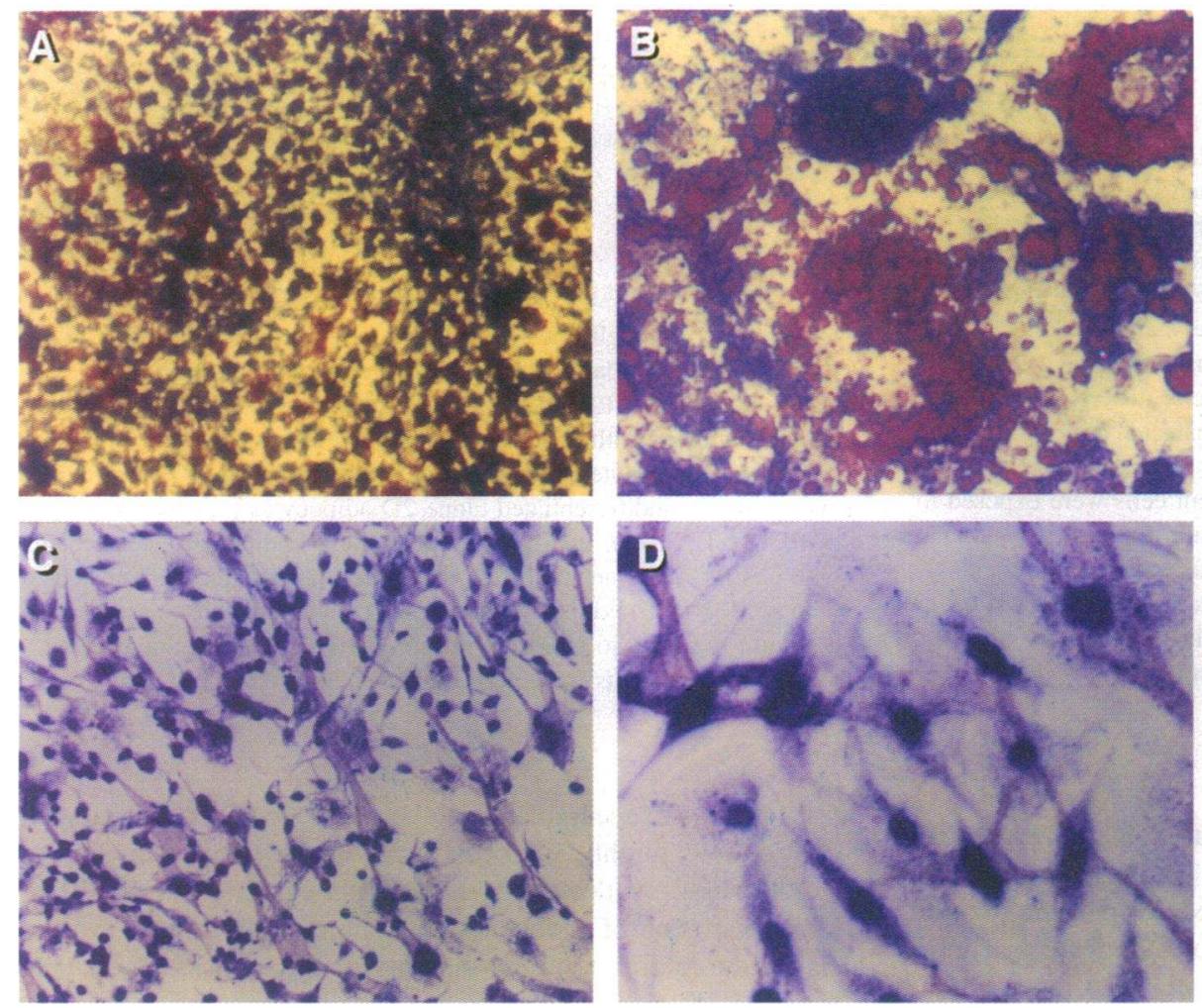

Figure 7. Photomicrographs of Oil red $O$ stained 3T3-F442A adipocytes. ( $A$ and B) Differentiated 3T3-F442A adipocytes transfected with pCEP4 vector without insert examined 8 days post confluence. $(C$ and $D$ ) Differentiated 3T3-F442A adipocytes transfected with pCEP4-HSL examined $15 \mathrm{~d}$ postconfluence. Cells were stained with Oil red $O$ after counter staining with hematoxylin-eosin. $A$ and $C$ : $\times 60 ; B$ and $D: \times 120$. due to the overexpression of HSL, with a presumably attendant increase in lipolysis, rather than an impairment in the cells' ability to synthesize lipids. To characterize lipid synthesis in the cells, the incorporation of $\left[{ }^{14} \mathrm{C}\right]$ glucose into cellular lipids was determined in control 3T3-F442A adipocytes and in HSL transfectant clones 2D and E4, both in the undifferentiated state and after $8 \mathrm{~d}$ of differentiation (Table $\mathrm{I}$ ). The rates of fatty acid synthesis were low in all the undifferentiated cells, and were similar in control and HSL transfectants. Although HSL transfectant clone E4 had similar rates of triglyceride and total lipid synthesis as control 3T3-F442A adipocytes, undifferentiated HSL transfectant clone 2D displayed increased triglyceride and total lipid synthesis when compared with control 3T3-
F442A adipocytes ( $P<0.01$ and $P<0.05$, respectively). After the cells reached confluence and were stimulated to differentiate, fatty acid, triglyceride and total lipid synthesis increased significantly in all three cell lines when compared to the respective undifferentiated cells $(P<0.001, P<0.05, P<0.01$, respectively for control, clone $2 \mathrm{D}$ and clone $\mathrm{E} 4$ ). While fatty acid synthesis increased in all three cell lines, it remained similar in control and HSL transfectants. In contrast, even though triglyceride and total lipid synthesis increased, they were both lower in the differentiated HSL transfectants than in control cells $(P<0.005)$; however, triglyceride and total lipid synthesis were similar in clones $2 \mathrm{D}$ and E4. Therefore, the HSL transfectants appear to be able to synthesize lipids and lipid
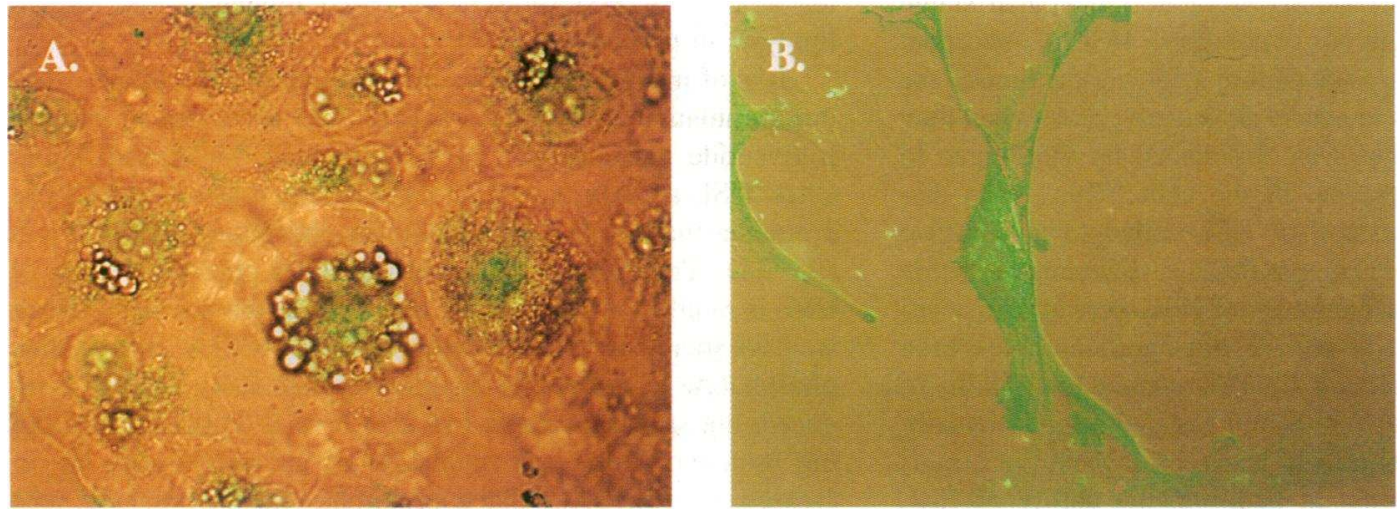

Figure 8. Confocal microscopy imaging of differentiated control $(A)$ and HSL transfected $(B)$ 3T3-F442A adipocytes. After permeabilization with $0.2 \%$ Triton X-100, the cells were incubated sequentially with rabbit serum, rabbit anti-HSL/fusion protein IgG, and goat anti-rabbit IgG-FITC fluorochrome conjugate. The slides were then examined by confocal microscopy for Nomarski DIC and fluorescent images as described in Methods. The fluorescent and Nomarski DIC images were merged by computer. Color was assigned arbitrarily; HSL immunofluorescence is shown in green. 

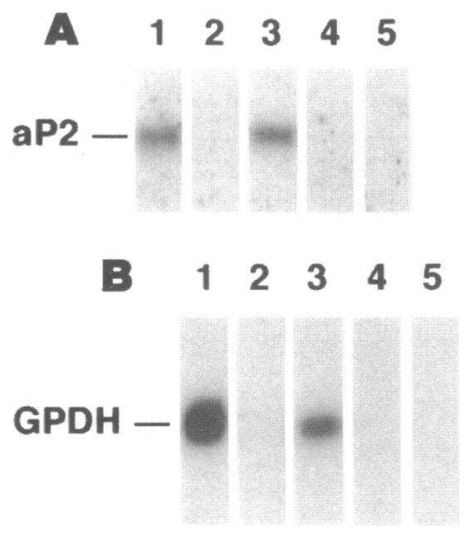

Figure 9. Northern blot of aP2 $(A)$ and GPDH $(B)$ mRNAs in adipocytes. Lane 1 , rat epididymal fat; lane 2 , undifferentiated cells transfected with pCEP4 vector without insert; lane 3 , differentiated cells transfected with pCEP4 vector without insert; lane 4, undifferentiated cells transfected with pCEP4-HSL; lane 5 , differentiated cells transfected with pCEP4-HSL. For differentiated cells, confluent cells were exposed to insulin for $\mathbf{4 8} \mathrm{hrs}$ to stimulate differentiation and then

assayed after 8-10 d. Total RNA (20 $\mu \mathrm{g}$ ) was electrophoresed on 1\% agarose gels, transferred to nylon and hybridized with either an aP2 or GPDH cDNA. Ethidium bromide staining demonstrated equivalent amounts of RNA in each lane (not shown).

synthesis increases following differentiation, albeit at a slightly reduced rate compared to differentiated control cells.

Since HSL activity can be regulated by phosphorylation, the state of phosphorylation of HSL was examined in control 3T3-F442A adipocytes and in HSL transfectant clones E4 and 2D (Fig. 13). In the basal state without stimulation of the cells by lipolytic agents, phosphorylated HSL could be detected in all three cell lines. Approximately 2-3-fold more phosphorylated HSL was observed in HSL transfectant clones E4 and 2D, respectively, when compared with differentiated control 3T3F442A adipocytes. However, HSL transfectant clones E4 and 2D have 3- and 10-fold as much immunoreactive HSL, respectively, as differentiated control 3T3-F442A adipocytes. Exposure of the cells to forskolin, which activates adenylate cyclase and stimulates PKA, increased the phosphorylation of HSL in control 3T3-F442A adipocytes $\sim 4$-fold; however, no stimulation was observed in either HSL transfectant clone E4 or 2D.

\section{Discussion}

In the current studies we have transfected the 3T3-F442A adipogenic cell line with a vector containing the entire coding region of rat HSL. We have successfully isolated and cloned stable transfectants that constitutively overexpress HSL. Concordant with the activity of HSL as a neutral triglyceride lipase, the ability of transfected cells to accumulate triglyceride when they differentiate into adipocytes was diminished by the degree to which HSL was overexpressed in the cells. Thus, cells displaying the highest expression of HSL failed to accumulate any cellular triglycerides when stimulated to differentiate, while cells overexpressing modest amounts of HSL were able to accumulate some intracellular triglyceride, but significantly less than control cells. Cells transfected with HSL retained their ability to synthesize lipids, with undifferentiated transfected cells actually synthesizing increased amounts of triglycerides and total lipids compared with control cells. In addition, the ability of HSL transfected cells to increase lipid synthesis following differentiation was preserved; however, the rates of triglyceride and total lipid, but not fatty acid, synthesis were lower in differentiated HSL transfectants than control cells. Thus, the failure of HSL

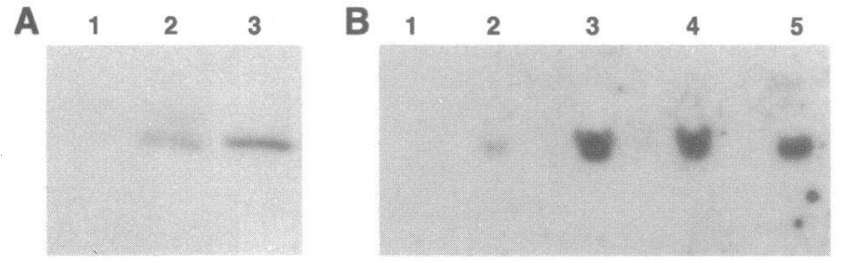

Figure 10. Immunoblot $(A)$ and Northern blot $(B)$ of HSL in 3T3F442A adipocyte cell lines. $(A)$ lane 1 , undifferentiated control 3T3F442A adipocytes; lane 2, undifferentiated clone $\mathrm{E} 4$ adipocytes transfected with PCEP4-HSL; lane 3, undifferentiated clone 2D adipocytes transfected with pCEP4-HSL. $(B)$ lane 1 , undifferentiated control 3T3-F442A adipocytes; lane 2, differentiated control 3T3-F442A adipocytes; lane 3 , undifferentiated clone 2D adipocytes transfected with pCEP4-HSL; lane 4, undifferentiated clone E4 adipocytes transfected with pCEP4-HSL; lane 5, differentiated clone E4 adipocytes transfected with pCEP4-HSL. For differentiated cells, confluent cells were exposed to insulin for $\mathbf{4 8} \mathrm{h}$ to stimulate differentiation and then assayed after 8-10 d. Experiments were performed as described in Fig. 2 and 3.

transfectants to accumulate cellular triglycerides compared with control cells might have been exaggerated by the reduction in cellular lipid synthesis observed. Although it is possible that clonal variation of endogenous functions, such as lipid synthesis, could contribute to the inability of the cells to accumulate triglyceride, this is unlikely to be a dominant factor since triglyceride accumulation among the HSL transfectants varied in proportion to the overexpression of vector-derived HSL without any differences in the ability of the HSL transfectants to synthesize lipids. Therefore, it appears that the overexpression of HSL is able to prevent cellular triglyceride accumulation, presumably by accelerating intracellular lipolysis. These results are consistent with our recent observations examining the physiological regulation of HSL in vivo. Food deprivation (15) and streptozotocin-induced diabetes (16) in rats caused an increase in the steady state levels of HSL mRNA and the amount of immunoreactive HSL protein that paralleled the rises in HSL activity and the reduction in adipose cell size observed with both of these physiological maneuvers. In addition, differences in the rate of basal lipolysis among various fat depots in the rat parallel the amount of immunoreactive HSL protein and the level of HSL mRNA found in the fat depot (32). Therefore, taken together these results are strong evidence in support of the concept that the amount of HSL present in a cell influences the rate of lipolysis in that cell.

It is of interest that the overexpression of HSL alone, without stimulation by lipolytic agents, was sufficient to prevent triglyceride accumulation in differentiated transfected adipocytes. HSL activity is usually regulated by fast-acting lipolytic hormones that activate the enzyme via phosphorylation by PKA $(33,34)$. This raises the question whether phosphorylation of HSL is required for hydrolytic activity. On the one hand, when we have treated cytosolic extracts of rat fat with $E$. coli alkaline phosphatase to maximally dephosphorylate HSL, activity is reduced, but still measurable ( $15.2 \pm 1.3$ vs. $4.0 \pm 0.6 \mathrm{nmol} / \mathrm{h}$ per mg protein). Moreover, sonication of fat cells causes an increased rate of lipolysis that approximates the maximal rate seen with adrenergic stimulation with forskolin (35). This increased lipolysis associated with sonication occurs without any discernible change in cyclic AMP. These results are similar in many ways to the observation that phosphorylation-induced increases 
A LPL Activity

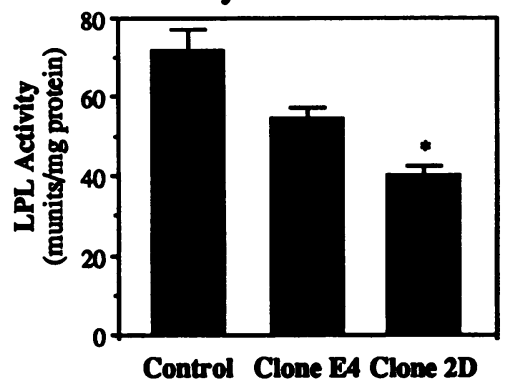

B Cellular Triglyceride

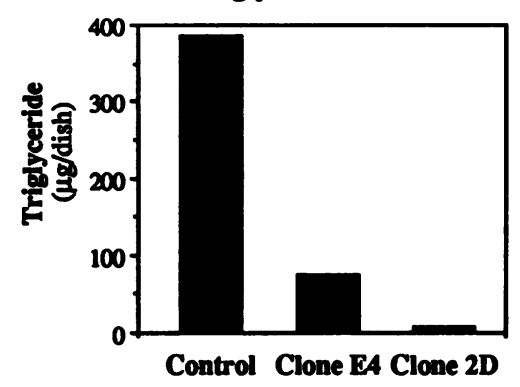

Figure 11. Expression of LPL activity $(A)$ and cellular triglyceride accumulation $(B)$ in differentiated 3T3F442A adipocyte cell lines. Confluent cells were exposed to insulin for $48 \mathrm{~h}$ to stimulate differentiation. LPL activity was measured $8 \mathrm{~d}$ later and cellular triglyceride content was measured after $\mathbf{8 ~} \mathrm{d}$ in control cells and after $15 \mathrm{~d}$ in clone $\mathrm{E} 4$ and clone $2 \mathrm{D}$ cells transfected with pCEP4-HSL. Results of LPL activity are the mean \pm SEM of triplicate wells, while cellular triglyceride is the average of duplicate wells. $* P<0.05$ compared to control cells. in HSL activity in vitro were only 2-4-fold compared with the up to 50-fold stimulation of lipolysis observed in intact fat cells. It has been suggested that the inability to detect a large increase in HSL activity was due to an increased surface area of lipid and, thus, a greater exposure of the lipid substrate to the enzyme in vitro. Likewise, a similar phenomenon might explain the increased lipolysis associated with sonication. Nevertheless, implicit in these explanations is the concept that nonphosphorylated HSL is catalytically active. On the other hand, the release of glycerol or FFA from unstimulated adipose cells is extremely low, suggesting that HSL activity within the cell is low in the basal state. However, it has been suggested that the phosphorylation of HSL not only increases the intrinsic activity of the enzyme, but also causes HSL to translocate from an aqueous cytosolic compartment to become associated with the lipid droplet (36). Moreover, this translocation may occur through the interaction of HSL with perilipin, an adipocyte specific protein that is located on the surface of the lipid droplet and is the major substrate in adipose cells for phosphorylation by PKA $(37,38)$. These observations raise the possibility that phosphorylation of HSL is not required for hydrolytic activity; rather, the effect of phosphorylation on enzymatic activation is relatively small and the dominant effect of phosphorylation of HSL is to mediate translocation, i.e., allow the enzyme to come in physical contact with intracellular lipid droplets. Results of our current experiments are consistent with this hypothesis. Thus, in contrast to control adipocytes where HSL is found primarily localized in a perinuclear distribution (see Fig. 8), when HSL

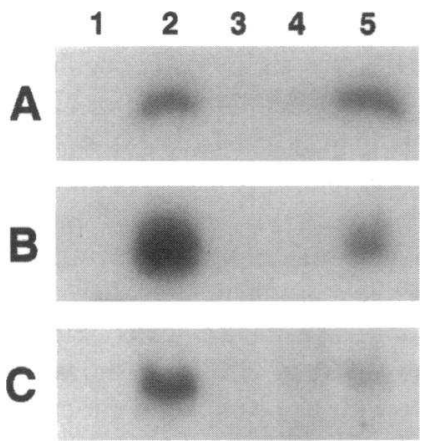

Figure 12. Expression of markers of adipocyte differentiation in 3T3-F442A adipocyte cell lines. $(A)$ Northern blot of LPL mRNA. $(B)$ Northern blot of aP2 mRNA. $(C)$ Northern blot of GPDH mRNA. Lane 1 , undifferentiated control cells; lane 2, differentiated control cells; lane 3, undifferentiated clone $2 \mathrm{D}$ cells transfected with pCEP4HSL; lane 4, undifferentiated clone $\mathrm{E} 4$ cells transfected with pCEP4-HSL; lane 5, differentiated clone E4 cells transfected with pCEP4-HSL. Total RNA $(20 \mu \mathrm{g})$ was electrophoresed on $1 \%$ agarose gels, transferred to nylon and hybridized with either an LPL, aP2, or GPDH cDNA. Ethidium bromide staining demonstrated equivalent amounts of RNA in each lane (not shown). Confluent cells were exposed to insulin for $48 \mathrm{~h}$ to stimulate differentiation and mRNA content measured after $8 \mathrm{~d}$. is markedly overexpressed, as in the current experiments, the enzyme is present in large amounts throughout the entire cell body, perhaps enabling lipid droplets to be exposed to the enzyme without the need for translocation.

Alternatively, our finding that the overexpression of HSL is sufficient to increase lipolysis to a degree that triglycerides cannot accumulate even in the absence of lipolytic stimulation does not necessarily mean that phosphorylation of HSL is unimportant. Clearly, HSL is phosphorylated in the HSL transfected cells under basal conditions and the amount of phosphorylated HSL in these cells is greater than that observed in differentiated control 3T3-F442A adipocytes (see Fig. 13). It is important to note that the HSL transfectants contain substantially more HSL protein than differentiated control 3T3-F442A adipocytes so that only a small portion of the HSL in the transfectants is phosphorylated in the basal state. Moreover, HSL can be phosphorylated at two different sites, one mediated by PKA that activates the enzyme $(33,39)$ and a secondary site that is mediated by several different kinases $(40,41)$ that occurs basally without stimulation (39) and impairs the ability of HSL to be activated by PKA (42). It is not apparent which of these sites on

Table I. Incorporation of $\left[{ }^{14} \mathrm{C}\right]$ Glucose into Cellular Lipids

\begin{tabular}{|c|c|c|c|}
\hline \multirow[b]{2}{*}{ Cells } & \multicolumn{3}{|c|}{$\left[{ }^{14} \mathrm{C}\right]$ Glucose incorporation into } \\
\hline & Fatty acids & Triglycerides & Total lipid \\
\hline & \multicolumn{3}{|c|}{ dpm/mg cell protein } \\
\hline \multicolumn{4}{|l|}{ Undifferentiated } \\
\hline Control 3T3-F442A & $204 \pm 82$ & $366 \pm 70$ & $827 \pm 121$ \\
\hline HSL transfectant clone 2D & $192 \pm 8$ & $838 \pm 22 *$ & $1990 \pm 132^{\ddagger}$ \\
\hline HSL transfectant clone E4 & $124 \pm 9$ & $433 \pm 29$ & $1211 \pm 44$ \\
\hline \multicolumn{4}{|l|}{ Differentiated } \\
\hline Control 3T3-F442A & $411 \pm 36$ & $2879 \pm 217$ & $4620 \pm 420$ \\
\hline HSL transfectant clone 2D & $582 \pm 67$ & $1174 \pm 70 *$ & $2887 \pm 97 *$ \\
\hline HSL transfectant clone E4 & $401 \pm 80$ & $1194 \pm 64 *$ & $2464 \pm 327 *$ \\
\hline
\end{tabular}

Cells were incubated with $1 \mu \mathrm{Ci} / \mathrm{ml}\left[\mathrm{U}_{-}{ }^{14} \mathrm{C}\right]$ glucose for $4 \mathrm{~h}$ at $37^{\circ} \mathrm{C}$. After scraping the cells into normal saline, the lipids were extracted by the Folch method (29) and separated by thin layer chromatography first using acetone until the solvent migrated $1 \mathrm{~cm}$ and then heptane:ethyl ether:acetic acid (75:25:2) as the solvent system. The locations corresponding to the migration of purified lipid standards were scraped and the radioactivity determined in a liquid scintillation spectrophotometer. Results are expressed as mean \pm SEM of triplicate wells and are representative of three separate experiments. $* P<0.01$ compared to respective control cells; ${ }^{\ddagger} P<0.05$ compared with control cells. 


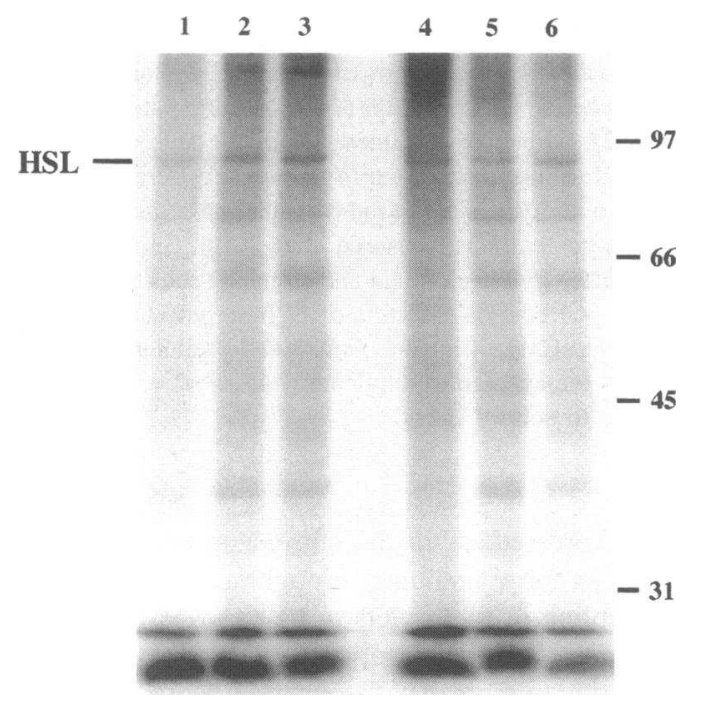

Figure 13. Phosphorylation of HSL in 3T3-F442A adipocyte cell lines. Cells were incubated in $\left[{ }^{32} \mathrm{P}\right]$ orthophosphate for $1 \mathrm{~h}$ before exposure to carrier or forskolin $\left(10^{-5} \mathrm{M}\right)$ for $10 \mathrm{~min}$. Cell extracts were immunoprecipitated with anti-HSL/fusion protein IgG as described in Methods. The immune complexes were electrophoresed on $10 \%$ polyacrylamide gels containing $8 \mathrm{M}$ urea and $0.1 \%$ SDS, and visualized on a PhophorImager ${ }^{\circledR}$. Lane 1 , differentiated control 3T3-F442A adipocytes exposed to carrier; lane 2, undifferentiated clone $\mathrm{E} 4$ cells transfected with pCEP4-HSL exposed to carrier; lane 3, undifferentiated clone 2D cells transfected with pCEP4-HSL exposed to carrier; lane 4, differentiated control 3T3-F442A adipocytes exposed to forskolin; lane 5, undifferentiated clone E4 cells transfected with pCEP4-HSL exposed to forskolin; lane 6 , undifferentiated clone 2D cells transfected with pCEP4-HSL exposed to forskolin. Molecular weight markers in $\mathrm{kD}$ are displayed on the right of the gel.

HSL is phosphorylated but it is possible that under the current conditions autocrine, paracrine, or normal cellular processes might cause phosphorylation of a portion of the large pool of HSL in these cells that is adequate to activate enough of the enzyme in the absence of lipolytic agents to mediate triglyceride hydrolysis.

The differentiation of adipocytes is a complex process that first involves commitment of the cells to differentiate, followed by the expression of early markers of differentiation, such as LPL, and then the appearance of later markers of differentiation, such as aP2, GPDH, HSL, fatty acid synthetase, insulin receptors, GLUT4, and adipsin (19). During differentiation, cellular triglycerides accumulate, resulting in the phenotypic feature of adipocytes. Using the appearance of LPL as the criterion for adipocyte differentiation, the cells transfected with HSL in the current experiments were able to differentiate when confluent cells were exposed to culture conditions that allow vector alone transfected cells or normal pre-adipogenic cells to undergo full differentiation. Even though LPL expression was somewhat delayed in the HSL transfectants, leading to slightly lower LPL activity than in control cells 1 wk postconfluence, LPL expression at subsequent time points was virtually indistinguishable between HSL transfectants and control cells. Thus, the HSL transfectants were able to commit towards differentiation and to progress normally through early adipocyte differentiation, although the accumulation of triglycerides was prevented in parallel to the degree to which HSL was overexpressed. Interest- ingly, later markers of adipocyte differentiation ( $\mathrm{aP} 2$ and GPDH) were not expressed normally in the HSL transfectants. The mechanisms whereby the early aberrant expression of HSL prevents the full complement of markers of normal differentiation from proceeding are not readily apparent. It is possible that the absence of triglyceride storage within the cell or an excess of intracellular fatty acids or other intermediates in the pathway represses the transcription of the aP2 and GPDH genes. While it is difficult to propose mechanisms how the presence or absence of cellular triglycerides could directly regulate gene expression, certainly the expression of some of the genes of differentiation can be regulated by intermediate factors. For example, fatty acids have been reported to induce aP2 (43) and retinoic acid to inhibit adipsin expression (44) without affecting other markers of differentiation. In view of the regulation of aP2 expression by fatty acids, an excess of intracellular fatty acids resulting from the overexpression of HSL would be expected to increase, rather than to attenuate, the expression of aP2. However, it is conceivable that an excess of intracellular fatty acids is toxic to the cells and thus prevents the expression of these genes. Alternatively, the possibility exists that the disruption of the complement of genes normally expressed late in adipocyte differentiation is not due to the action of HSL as a neutral triglyceride lipase, but to its actions as a neutral cholesterol esterase. In this circumstance, the overexpression of HSL might lead to an increase in cellular unesterified cholesterol that would inhibit cholesterol biosynthesis and possibly disturb sterol intermediates that might be required for the expression of genes in late adipocyte differentiation. Finally, could clonal selection have contributed to the lack of expression of late markers of adipocyte differentiation and the inability of the cells to accumulate triglyceride? Although it has been shown that culturing preadipocytes in clonal conditions lowers their ability to terminally differentiate (45), this is unlikely to be a significant factor in the current experiments since both the expression of late markers of differentiation and triglyceride accumulation among the HSL transfectants varied in proportion to the overexpression of vector-derived HSL and cells transfected with vector alone and selected under similar conditions expressed late markers of differentiation and accumulated triglyceride to the same extent as control 3T3-F442A cells.

As opposed to the inhibition of the expression of aP2 and GPDH by the overexpression of HSL, no consistent effects of HSL overexpression on LPL expression were observed in differentiated adipocytes. This is interesting in light of the reports suggesting that LPL and HSL are reciprocally regulated $(46,47)$. Our current data suggest that neither HSL nor HSLmediated changes in lipid metabolism affect LPL expression. Therefore, any reciprocal changes in the expression of HSL and LPL must be due to variations in the responses of these lipases to effectors rather than due to any interaction or. regulation occurring between the lipases or their products.

In conclusion, by transfecting 3T3-F442A cells with a pCEP4-HSL vector, the overexpression of HSL was shown to prevent adipocytes from taking on the appearance of fat cells, i.e., triglyceride accumulation. Thus, modifying the quantity of HSL enzyme within a fat cell can influence the amount of triglyceride that a cell can accumulate. Moreover, by overexpressing HSL and/or disrupting cellular lipid pathways, the expression of some lipogenic enzymes that normally appear late in adipocyte differentiation are repressed. Thus, the level of expression of HSL appears both to determine the amount of 
cellular triglycerides an adipocyte can accumulate and to regulate, directly or indirectly, the expression of late markers of adipocyte differentiation. The adipocyte cell lines overexpressing HSL which have been isolated might prove to be useful models for exploring various stages of adipocyte differentiation and the interaction of different lipid pathways on gene expression during differentiation.

\section{Acknowledgments}

We thank S. Patel and V. Natu for excellent technical assistance.

This work was supported in part by Research Grants from the Research Service of the Department of Veterans Affairs and by grants HL42865 and DK-46942 (F. B. Kraemer) and HL-39362 (M. C. Komaromy) from the National Institutes of Health.

\section{References}

1. Dole, V. P. 1956. A relation between non-esterified fatty acids in plasma and the metabolism of glucose. J. Clin. Invest. 35:150-154.

2. Gordon, R. S., Jr., and A. Cherkes. 1956. Unesterified fatty acids in human blood plasma. J. Clin. Invest. 35:206-212.

3. Larsson, B. 1991. Obesity, fat distribution and cardiovascular disease. Int. J. Obes. 15:53-57.

4. Bjorntorp, P. 1991. Adipose tissue distribution and function. Int. J. Obes. 15:67-81.

5. Kissebah, A. H. 1991. Insulin resistance in visceral obesity. Int. J. Obes. 15:109-115.

6. Vaughan, M., J. E. Berger, and D. Steinberg. 1964. Hormone-sensitive lipase and monoglycerol lipase activities in adipose tissue. J. Biol. Chem. 239:401-409.

7. Fredrikson, G., P. Stralfors, N. O. Nilsson, and P. Belfrage. 1981. Hormonesensitive lipase of rat adipose tissue. purification and some properties. J. Biol. Chem. 256:6311-6320.

8. Stralfors, P., H. Olsson, and P. Belfrage. 1987. Hormone-sensitive lipase. In The Enzymes. P. D. Boyer, and E. G. Krebs, editors. Academic Press, New York. 147-177.

9. Tornqvist, H., and P. Belfrage. 1976. Purification and some properties of a monoacylglycerol hydrolyzing enzyme of rat adipose tissue. J. Biol. Chem. 251:813-819.

10. Fredrikson, G., H. Tornqvist, and P. Belfrage. 1986. Hormone-sensitive lipase and monoacylglycerol lipase are both required for complete degradation of adipocyte triacylglycerol. Biochim. Biophys. Acta. 876:288-293.

11. Fredrikson, G., and P. Belfrage. 1983. Positional specificity of hormonesensitive lipase from rat adipose tissue. J. Biol. Chem. 258:14253-14256.

12. Walsh, D. A., J. P. Perkins, and E. G. Krebs. 1968. An adenosine 3',5'monophosphate-dependent protein kinase from rabbit skeletal muscle. J. Biol. Chem. 243:3763-3765.

13. Steinberg, D., and J. K. Huttunen. 1972. The role of cyclic AMP in activation and phosphorylation of a purified hormone-sensitive lipase. Adv. Cyclic Nucleotide Res. 1:47-62.

14. Steinberg, D., S. E. Mayer, J. C. Khoo, E. A. Miller, R. E. Miller, B. Fredholm, and R. Eichner. 1975. Hormonal regulation of lipase, phosphorylase, and glycogen synthase in adipose tissue. Adv. Cyclic Nucleotide Res. 5:549-568.

15. Sztalryd, C., and F. B. Kraemer. 1994. Regulation of hormone sensitive lipase during fasting. Am. J. Physiol. 266 (Endocrinol. Metab. 29):E179-E185.

16. Sztalryd, C., and F. B. Kraemer. 1994. Regulation of hormone-sensitive lipase in streptozotocin-treated rats. FASEB (Fed. Am. Soc. Exp. Biol.) J. 8:A702.

17. Green, H., and O. Kahinde. 1974. Sublines of mouse 3T3 cells that accumulate lipid. Cell. 1:113-116.

18. Green, H., and O. Kahinde. 1975. An established preadipose cell line and its differentiation in culture. II. Factors affecting the adipose conversion. Cell. 5:19-27.

19. Ailhaud, G., P. Grimaldi, and R. Negrel. 1992. Cellular and molecular aspects of adipose tissue development. Annu. Rev. Nutr. 12:207-233.

20. Holm, C., T. G. Kirchgessner, K. L. Svenson, A. J. Lusis, P. Belfrage, and M. C. Schotz. 1988. Nucleotide sequence of rat adipose hormone sensitive lipase cDNA. Nucleic Acids Res. 16:9879.

21. Sambrook, J., E. F. Fritsch, and T. Maniatis. 1989. Molecular Cloning: A Laboratory Manual. Cold Spring Harbor Laboratory Press, Cold Spring Harbor, NY.

22. Komaromy, M., and M. Reed. 1991. Expression of rat hepatic lipase in heterologous systems: evidence for different sites for interface binding and catalysis. J. Lipid Res. 32:963-975.

23. Kraemer, F. B., S. Patel, M. S. Saedi, and C. Sztalryd. 1993. Detection of hormone-sensitive lipase in various tissues. I. Expression of an HSL/bacterial fusion protein and generation of anti-HSL antibodies. J. Lipid Res. 34:663-671.

24. Kraemer, F. B., K. Tavangar, and A. R. Hoffman. 1991. Developmental regulation of hormone-sensitive lipase mRNA in the rat: changes in steroidogenic tissues. J. Lipid Res. 32:1303-1310.

25. Chen, Y.-D. I., J. Howard, V. Huang, F. B. Kraemer, and G. M. Reaven. 1980. Dissociation between plasma triglyceride concentration and tissue lipoprotein lipase deficiency in insulin-deficient rats. Diabetes. 29:643-647.

26. Tavangar, K., Y. Murata, S. Patel, J. E. Kalinyak, M. E. Pedersen, J. F. Goers, A. R. Hoffman, and F. B. Kraemer. 1992. Developmental regulation of lipoprotein lipase in rats. Am. J. Physiol. 262:E330-E337.

27. Wise, L. S., and H. Green. 1979. Participation of one isoenzyme of cytosolic glycerophosphate dehydrogenase in the adipose conversion of 3T3 cells. J. Biol. Chem. 254:273-275.

28. Levacher, C., C. Sztalryd, and L. Picon. 1985. Lipogenesis as related to endocrine control of adipose cellularity in the rat. Reprod. Nutr. Dev. 1B:169173.

29. Folch, J., M. Lees, and G. H. S. Stanley. 1951. A simple method for the isolation and purification of total lipids from animal tissues. J. Biol. Chem. 193:497-509.

30. Li Clie, R. D. 1944. Various oil-soluble dyes as fat stains in the superstaurated isopropanol technique. Stain Technol. 19:55.

31. Holm, C., P. Belfrage, and G. Fredrikson. 1987. Immunological evidence for the presence of hormone-sensitive lipase in rat tissue other than adipose tissue. Biochem. Biophys. Res. Commun. 148:99-105.

32. Sztalryd, C., and F. B. Kraemer. 1994. Differences in hormone sensitive lipase expression in white adipose tissue from various anatomical locations of the rat. Metabolism. 43:241-247.

33. Stralfors, P., P. Bjorgell, and P. Belfrage. 1984. Hormonal regulation of hormone-sensitive lipase in intact adipocytes: identification of phosphorylation sites and effects on the phosphorylation by lipolytic hormones and insulin. Proc. Natl. Acad. Sci. USA. 81:3317-3321.

34. Yeaman, S. J. 1990. Hormone-sensitive lipase-a multipurpose enzyme in lipid metabolism. Biochim. Biophys. Acta. 1052:128-132.

35. Okuda, H., C. Morimoto, and T. Tsujita. 1992. Relationship between cyclic AMP production and lipolysis induced by forskolin in rat fat cells. J. Lipid Res. 33:225-231.

36. Egan, J. J., A. S. Greenberg, M.-K. Chang, S. A. Wek, M. C. Moos, Jr, and C. Londos. 1992. Mechanism of hormone-stimulated lipolysis in adipocytes: translocation of hormone-sensitive lipase to the lipid storage droplet. Proc. Natl. Acad. Sci. USA. 89:8537-8541.

37. Greenberg, A. S., J. J. Egan, S. A. Wek, N. B. Garty, E. J. Blanchettemackie, and C. Londos. 1991. Perilipin, a major hormonally regulated adipocytespecific phosphoprotein associated with the periphery of lipid storage droplets. $J$. Biol. Chem. 266:11341-11346.

38. Greenberg, A., J. Egan, S. Wek, M. Moos Jr, C. Londos, and A. Kimmel. 1993. Isolation of cDNAs for perilipins $A$ and $B$ : sequence and expression of lipid droplet-associated proteins of adipocytes. Proc. Natl. Acad. Sci. USA 90:12035-12039.

39. Garton, A. J., D. G. Cambell, P. Cohen, and S. J. Yeaman. 1988. Primary structure of the site on bovine hormone-sensitive lipase phosphorylated by cyclic AMP-dependent protein kinase. FEBS (Fed. Eur. Biochem. Soc.) Lett. 229:6872.

40. Olsson, H., P. Stralfors, and P. Belfrage. 1986. Phosphorylation of the basal site of hormone-sensitive lipase by glycogen synthase kinase-4. FEBS (Fed. Eur. Biochem. Sco.) Lett. 209:175-180.

41. Garton, A. J., D. G. Campbell, D. Carling, D. G. Hardie, R. J. Colbran, and S. J. Yeaman. 1989. Phosphorylation of bovine hormone-sensitive lipase by the AMP-activated protein kinase. Eur. J. Biochem. 179:249-254.

42. Garton, A. J., and S. J. Yeaman. 1990. Identification and role of the basal phosphorylation site on hormone-sensitive lipase. Eur. J. Biochem. 191:245-250.

43. Amri, E. Z., B. Bertrand, G. Ailhaud, and P. Grimaldi. 1991. Regulation of adipose cell differentiation .1. fatty acids are inducers of the aP2 gene expression. J. Lipid Res. 32:1449-1456.

44. Antras, J., F. Lasnier, and J. Pairault. 1991. Adipsin gene expression in 3T3-F442A adipocytes is posttranscriptionally down-regulated by retinoic acid. J. Biol. Chem. 266:1157-1161.

45. Lin, F.-T., and M. D. Lane. 1992. Antisense CCAAT/enhancer-binding protein RNA suppresses coordinate gene expression and triglyceride accumulation during differentiation of 3T3-L1 preadipocytes. Genes \& Dev. 6:533-544.

46. Patten, R. L. 1970. The reciprocal regulation of lipoprotein lipase activity and hormone-sensitive lipase activity in rat adipocytes. J. Biol. Chem. 245:55775584.

47. Arner, P., J. Bolinder, P. Engfeldt, and H. Lithell. 1983. The relationship between the basal lipolytic and lipoprotein lipase activities in human adipose tissue. Int. J. Obesity. 7:167-172. 